\title{
A practical model for identification of children at risk of excess energy intake in the developing world
}

\author{
Pamela S Gaskin ${ }^{1, *}$, Peter Chami ${ }^{2,3}$, Justin Ward ${ }^{3}$, Gabriela Goodman ${ }^{4}$, Bernd Sing ${ }^{3}$, \\ Maria D Jackson ${ }^{5}$ and Hedy Broome ${ }^{1}$ \\ ${ }^{1}$ Faculty of Medical Sciences, University of the West Indies, Errol Waldron Building, Jemmotts Lane, Cave Hill, St \\ Michael, Barbados: ${ }^{2}$ The Warren Alpert Medical School of Brown University, Providence, RI, USA: ${ }^{3}$ Faculty of Pure \\ and Applied Sciences, University of the West Indies, Cave Hill, Barbados: ${ }^{4}$ School of Dietetics and Human Nutrition, \\ McGill University, Montreal, QC, Canada: ${ }^{5}$ Faculty of Medical Sciences, University of the West Indies, Mona, \\ Jamaica
}

Submitted 5 July 2018: Final revision received 6 December 2018: Accepted 14 January 2019: First published online 8 March 2019

\begin{abstract}
Objective: We describe diet quality by demographic factors and weight status among Barbadian children and examine associations with excess energy intake (EI). A screening tool for the identification of children at risk of excess EI was developed.

Design: In a cross-sectional survey, the Diet Quality Index-International (DQI-I) was used to assess dietary intakes from repeat $24 \mathrm{~h}$ recalls among 362 children aged 9-10 years. Participants were selected by probability proportional to size. A model to identify excess energy intake from easily measured components of the DQI-I was developed.

Setting: Barbados.

Participants: Primary-school children in Barbados.

Results: Over one-third of children were overweight/obese, and mean EI for boys $(8644$ (sE 174.5$) \mathrm{kJ} / \mathrm{d}(2066$ (sE 41.7) kcal/d)) and girls (8912 (sE 169.9) kJ/d (2130 (se 40.6) $\mathrm{kcal} / \mathrm{d}$ )) exceeded the RDA. Children consuming a variety of food groups, more vegetables and fruits, and lower percentage energy contribution from empty-calorie foods showed reduced likelihood of excess EI. Intake of more than $2400 \mathrm{mg} \mathrm{Na} / \mathrm{d}$ and higher macronutrient and fatty acid ratios were positively related to the consumption of excess energy. A model using five DQI-I components (overall food group variety, variety for protein source, vegetables, fruits and empty calorie intake) had high sensitivity for identification of children at risk of excess EI.

Conclusions: Children's diet quality, despite low intakes of fruit and vegetables, was within acceptable ranges as assessed by the DQI-I and RDA; however, portion size was large and EI high. A practical model for identification of children at risk of excess EI has been developed.
\end{abstract}

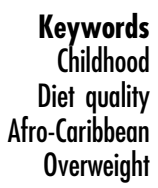

Keywords

Childhood Afro-Caribbean Overweight
Caribbean countries now face rising levels of obesity and other chronic diseases among children. Yet there are few published data to guide the identification of children at risk. Diet quality is important because of its relationship to obesity $^{(1)}$ and some research suggests that diet quality scores could be important to interventions designed to reduce obesity ${ }^{(2)}$. Consumption of high-energy, lownutrient foods has been a particular focus because they are thought to replace 'healthy' foods ${ }^{(3)}$. Studies have described the effects of fast foods ${ }^{(4)}$, added sugar, beverage consumption ${ }^{(5)}$ as well as specific foods such as apples $^{(6)}$ and mangoes ${ }^{(7)}$ on diet quality. Traditionally, dietary adequacy has been the focus of dietary assessments among children in the Caribbean and was associated with undernutrition and nutrient deficiency disease $^{(8)}$, which has decreased appreciably in recent times ${ }^{(9)}$. These countries now face rising levels of obesity and other chronic disease among children ${ }^{(10)}$, hence dietary recommendations that may reduce cardiovascular risks have become a major public health thrust. A recent assessment of adult dietary patterns globally indicated that women and men in Barbados ranked first and second, respectively, among 187 countries for high diet quality regarding the consumption of ten healthy food items in 
$2010^{(11)}$. Diets among children appear to be similar ${ }^{(12)}$, yet childhood overweight is prevalent ${ }^{(13)}$. Demographic and socio-economic factors identify children at risk of high energy intake and obesity in the developed world ${ }^{(14)}$. Notwithstanding, these associations have not been well documented for developing countries with recent experience of the nutrition transition.

In an early study of Barbadian adolescents, girls, compared with boys, were more likely to be overweight ${ }^{(15)}$. The Barbados Children's Health and Nutrition Study (BCHNS) showed high consumption of 'empty calories' ( $21 \%$ of total energy derived from sugar-added beverages) and infrequent intake of $\operatorname{milk}^{(12)}$.

Given the inverse association of socio-economic status (SES) with overweight ${ }^{(16)}$, diet quality ${ }^{(17)}$ and food-related practices, it might be expected that levels of overweight and excess energy intake would be higher among children from single-parent or multigenerational homes. We hypothesized that girls, overweight children, children from less privileged homes and those whose diets exceed the age/sex recommendations for energy intake would have diets comprising high proportions of foods and nutrients associated with chronic disease. Diet quality indices such as the Diet Quality Index-International (DQI-I) provide tools for assessing $\operatorname{such}^{(18)}$. Given that the moderation category of the DQI-I captures nutrients associated with the development of metabolic disease, we paid particular attention to the components in this category. The index adjusts for energy intake, an approach that is considered preferable with respect to assessment of correlations of nutrients with biomarkers ${ }^{(18)}$. In addition, because most adults who are overweight were not overweight as children it is important to identify children at risk of overweight from factors other than their current anthropometry. Diet is clearly important to the development of obesity, so identification of dietary patters that portend obesity would be welcome.

In the present study, we therefore describe the diet quality of Barbadian children and highlight demographic and weight status differences in dietary components among children aged 9-10 years. We further sought to develop a screening model to identify children at increased risk of excess energy intake.

\section{Methods}

A cross-sectional survey was conducted on 362 children aged 9-10 years attending a representative sample of government primary schools in Barbados.

\section{Sampling}

The main study from which data for the present paper were taken was designed to provide nationally representative data and prevalence estimates for the nutritional status of 9-10-year-old children in Barbados ${ }^{(13)}$. Probability proportional to size was used to select the schools included. This allows larger schools to be more likely to be selected $^{(19)}$. There were seventy-four public primary schools in Barbados and $85.7 \%$ of all children of primaryschool age attended government schools in 2010-2011. All students in Class 3 (Grade 5 equivalent) were eligible for participation in the study. All schools selected agreed to participate in the study. The Ministry of Education provided a list of the number of children aged 9-10 years in each school. These were arranged in a sequential list and a selection of clusters was arrived at by calculating a sampling interval. The number of children in each school ranged widely (thirteen to 140 children). From a randomly selected starting point, fifteen schools were chosen and forty-two children per school were selected within age and sex categories. Where there were too few children to fill the categories, another school of comparable characteristics in the neighbourhood was drawn to complete the age and sex groups. If children refused to participate in the study, recruitment continued until a total of forty-two students were enrolled in each cluster. For the current study, alternate children were selected for inclusion in the dietary study.

\section{Recruitment}

An a priori decision was taken to select a sub-sample of students to examine dietary behaviours, in view of limited resources. At enrolment, alternate children were systematically enrolled for dietary measures. All children approached agreed to participate. Of the 385 who provided dietary intake measures, twenty-three provided only one $24 \mathrm{~h}$ recall, resulting in 362 with adequate measures. There were no significant differences in age, BMI $Z$-score or other anthropometric measurements among children who had dietary measures compared with those who did not. Informed written consent was obtained from parents and assent from children. All measurements were obtained by trained observers. Quality control included reliability checks of measurements by the supervisor prior to and during data collection. Inter-observer reliabilities for height were conducted prior to the start of the study ( $n$ 32) and intra-class correlation coefficients were high $(>0 \cdot 97)$. Scales were calibrated by use of a standard weight $(3 \mathrm{~kg})$. The fieldwork supervisor visited the schools to ensure that the measurement protocols for dietary intakes were followed. Data were collected from September 2010 to April 2011.

\section{Measurements}

Body composition

All measurements were conducted under semi-private conditions prior to lunch and at least $2 \mathrm{~h}$ after the last meal. Children were measured in uniform, with shoes and socks removed. Height was measured using a stadiometer 
(HM200P; Charder Co. Ltd, USA), weight using a digital scale and foot-to-foot measurement of bioimpedance analysis using the Tanita TBF-300 Body Composition Analyser. Standing height and weight were measured to $0 \cdot 1 \mathrm{~cm}$ and $0 \cdot 1 \mathrm{~kg}$, respectively, following standard procedures $^{(20)}$. Height and BMI were converted to $Z$-scores using the WHO growth reference and AnthroPlus program $^{(21)}$. Two consecutive measurements were performed for each anthropometric measure. The mean was used in data analyses. Children's weight status was categorized using the WHO references ${ }^{(21)}$.

\section{Housebold type}

Given that we did not have access to SES measures from parents, household type (single-parent or two-parent) was used as a proxy measure of SES. To assess household type children were asked whether they lived in the home with both parents (mother and father), one parent (single), or with one parent and others such as grandmothers or aunts (extended family). We aggregated the single and extended families into one category.

\section{Dietary intake}

As indicated earlier, a sub-sample of students ( $n$ 362) provided dietary information to determine diet quality of the 9-10-year-olds. Dietary intakes were estimated from the mean of three $24 \mathrm{~h}$ recalls administered on nonconsecutive days including a weekend day. Portions were carefully estimated using food models (Nasco, USA), household measures and utensils, in conjunction with a detailed description of the food and the method of preparation, where applicable. For composite dishes, the amount of each ingredient used in the recipe was estimated by the researcher. Household measurements recorded were converted into food weights in grams using the software Nutritionist Pro ${ }^{\mathrm{TM}}$ version 5.3.0 (Axxya Systems, USA). If cooked dishes were not found in the database of Nutritionist Pro, the investigator made an original recipe from standard cookbooks for each dish (per $100 \mathrm{~g}$ ) and then the quantitative information was entered in the Nutritionist Pro software. Daily amounts of nutrients were generated by referencing and accessing the latest national dietary database that the software was connected to by default. US Department of Agriculture reference items were selected when available. Mean energy and nutrient intakes were recorded. A priori we excluded children who had only one $24 \mathrm{~h}$ dietary recall or who reported daily energy intakes of less than $2092 \mathrm{~kJ}$ $(500 \mathrm{kcal})$ or more than $20920 \mathrm{~kJ}$ (5000 kcal); twenty-three children were excluded from analysis.

The DQI-I was used to assess the quality of the diet and conformance to the Dietary Guidelines for Americans $2010^{(18)}$. The DQI-I uses scores for each dietary component and summarizes these into four main categories: variety, adequacy, moderation and overall balance. Each category is given a score dependent on energy intake. The scores for all four categories are summed, resulting in the total DQI-I score which ranges from 0 to 100 (0 being the lowest and 100 the highest possible score). Under each of these categories specific components of diet are assessed: two variety components (overall food group variety and within food group variety); eight adequacy components (intakes of vegetables, fruits, grains, fibre, protein, iron, calcium and vitamin C); five moderation components (intakes of total fat, saturated fat, cholesterol, sodium and empty-calorie foods (i.e. foods with low nutrient density)); and two overall balance components (macronutrient ratio and fatty acid ratio based on servings, g/d or RDA).

Excess energy intake was calculated based on US Department of Agriculture estimates of the daily energy needs for Americans by age, gender and physical activity ${ }^{(22)}$. We categorized children into 'within energy' or 'excess of energy' intake groups from reported intake. Energy from beverages was included in diet quality calculations.

\section{Statistical analyses}

The dietary data set was cleaned and summarized using the technical computing system Mathematica version 10.0 (Wolfram, USA); all subsequent statistical analysis was carried out using the statistical software package Stata version 14.0 and the statistical software $\mathrm{R} \times 64$ version 3.2.3. Children's weight status was categorized using the WHO references ${ }^{(21)}$.

Differences in continuous variables expressed as means with their standard errors were examined by ANOVA and differences in proportions by were examined by $\chi^{2}$ analyses.

A penalised regression - in the present case, a least absolute shrinkage and selection operator (LASSO) regression - was applied in order to attain an optimal model covariate subset for membership in the excess energy intake group using the DQI-I components as predictor variables (Table 3). The dependent variable was energy intake (from $24 \mathrm{~h}$ recalls) with age, sex, BMI $Z$-score and household type controlled. Variables that enter our proposed model early show the most predictive ability, whereas variables that enter late show less. Thus as $\lambda$, the weight given to the regularization term ( $L 1-$ Norm) approaches zero, the loss function of our model approaches the ordinary least-squares:

$$
\beta_{\text {lasso }}=\arg \min [R S S(\beta)+\lambda \times L 1-\operatorname{Norm}(\beta)] .
$$

Binary logistic regression was then carried out to select the most parsimonious model. Model fit was judged by employing the Hosmer-Lemeshow test. OR were reported for all significant covariates $(z<0.05$ and all $95 \% \mathrm{CI})$. Marginal effects at the means (MEM), i.e. the contribution of each DQI-I dietary component to the model, were calculated for interpretation of the predictive probabilities of all significant independent variables, with age, sex and household type nested. The models' classification, log- 
Table 1 Demographic, anthropometric and socio-economic variables and energy intake of children aged 9-10 years (n 362), Barbados Children's Health and Nutrition Study (BCHNS), September 2010April 2011

\begin{tabular}{|c|c|c|c|c|}
\hline \multirow[b]{2}{*}{ Variable } & \multicolumn{2}{|c|}{ Boys ( $n$ 174) } & \multicolumn{2}{|c|}{ Girls ( $n$ 188) } \\
\hline & Mean or Median & SD or IQR & Mean or Median & SD or IQR \\
\hline Age (years) & $9 \cdot 69$ & 0.36 & $9 \cdot 71$ & 0.34 \\
\hline Height $(\mathrm{cm})$ & 139.29 & 6.91 & 141.66 & $7 \cdot 34$ \\
\hline Weight (kg) & 35.60 & 11.00 & 37.79 & $10 \cdot 26$ \\
\hline $\mathrm{BMI}\left(\mathrm{kg} / \mathrm{m}^{2}\right)$ & $18 \cdot 11$ & $4 \cdot 27$ & 18.63 & 4.04 \\
\hline BMI Z-score, median and IQR & 0.47 & 1.61 & 0.57 & 1.41 \\
\hline$\%$ Two-parent household & 43.1 & & $49 \cdot 4$ & \\
\hline$\%$ Overweight/obese ( $\geq 1 \mathrm{SD}$ ) & $33 \cdot 0$ & & $41 \cdot 0$ & \\
\hline$\%$ Excess energy intaket & 64.4 & & $79 \cdot 8^{\star \star}$ & \\
\hline
\end{tabular}

IQR, interquartile range.

Values are presented as mean and standard deviation, unless indicated otherwise.

**Difference significant at the $1 \%$ level.

†Percentage with energy intake in excess of the US Department of Agriculture's age/sex energy intake recommendations ${ }^{(22)}$.

likelihood and the likelihood-ratio $\chi^{2}$ statistic were used to compare the parsimonious model with a proposed more practically applicable model which was nested within the parsimonious model. Finally, a multilevel linear regression model was employed to ascertain the percentage contribution from the children's intake of empty calories to the overall model variance. We evaluated our model for planar collinearity using the sub-component scores and investigated the marginal effects of significant components. Our criteria for removal of cases was variance within 1 SD on four or more covariates.

\section{Results}

Table 1 displays the characteristics of participants. The mean age of boys (9.7 (sD 0.4) years) and girls (9.7 (SD 0.3) years) was similar. The sex differences in weight status did not reach statistical significance. However, girls were more likely to report excess energy intake $(P<0 \cdot 01$; Table 1$)$.

Table 2 shows daily mean intakes of energy and nutrients. The mean daily energy intake of boys (8644 (SE $174.5) \mathrm{kJ} / \mathrm{d}(2066$ (SE 41.7) kcal/d)) and girls (8912 (SE $169.9) \mathrm{kJ} / \mathrm{d}$ (2130 (sE 40.6) kcal)) was similar. Mean reported intakes were higher than the RDA $(6694-7531 \mathrm{~kJ} /$ $\mathrm{d}(1600-1800 \mathrm{kcal} / \mathrm{d}))$ for both sexes. The proportion of energy contributed by macronutrients was within the RDA for both girls and boys; however, energy from saturated fats exceeded the recommendations ${ }^{(22)}$. The percentage of energy from sugar was significantly higher among girls (26.1 \%) than boys (24.6\%; $P<0.05$; Table 2$)$.

Most children $72(95 \%$ CI 68,77$) \%$ reported greater daily energy intake than recommended for their age/sex category $^{(22)}$. Children reporting excess energy intake had higher unadjusted diet quality scores (58.09 (SE 0.50)) compared with children whose diets fell within the energy recommendations (55.89 (sE 0.90); $P=0.028$ ).

The mean DQI-I scores were as follows: total DQI-I, 57.5 ( $\mathrm{SE} 0.45 ;$ maximum $=100)$; variety, 15.0 ( $\mathrm{SE} 2 \cdot 0$; maximum $=20)$; adequacy, $28 \cdot 2(\mathrm{se} 0 \cdot 21 ;$ maximum $=40)$; moderation, $12 \cdot 8$ ( $\mathrm{sE} 0 \cdot 28$; maximum $=30$ ); overall balance, 1.47 (SE 0.1; maximum $=10$ ). Thirty-seven per cent of children attained a total DQI-I score of 60 or greater (data not shown). Table 3 summarizes the overall and subcomponents of diet quality scores. The quality of the diet was varied. Almost $60 \%$ of children reported diets with none or one food group missing per day. Most children $(85.1 \%)$ had protein from at least two sources per day. With respect to the adequacy of intakes, more than twothirds $(69.0 \%)$ of children reported low vegetable intake and $3.6 \%$ of children reported diets devoid of vegetables. Approximately $60 \%$ of children ate less than $50 \%$ of the recommended serving of fruits and included $13.0 \%$ of children who reported that they did not consume fruits during the period under review. Intake of the recommended levels of grain consumption was reported by $35.9 \%$ of students, however few students (5.4\%) ate less than one-half of the recommended levels. Forty per cent of children met the recommendations for grain intake. The vast majority of students met or exceeded recommended levels for protein (94.5\%), Fe (88.1\%) and vitamin C $(84.0 \%)$. Ca intake was low; $1.4 \%$ of children met the RDA for $\mathrm{Ca}$ and $66.2 \%$ reported intakes less than $50 \%$ of the recommended level.

Examination of the moderation category showed that more than one-half children reported high total fat (60.5\%) and saturated fat (53.9\%) intakes; nevertheless, almost three-quarters $(72.4 \%)$ of children consumed cholesterol at desirable levels (Table 3). Forty per cent of children consumed $\leq 2400 \mathrm{mg} \mathrm{Na} / \mathrm{d}$. Whereas less than $10 \%$ of children reported diets that contained $\leq 3 \%$ of total energy consumed as empty calories, $55.2 \%$ of children derived $>10 \%$ of energy from empty-calorie foods.

\section{Differences by sex, weight status and household type}

Stratification of the DQI-I scores by sex revealed that there was a tendency for girls to have better overall diet quality 
Table 2 Comparison of the mean and median daily energy and nutrient intakes of children aged 9-10 years ( $n$ 362), Barbados Children's Health and Nutrition Study (BCHNS), September 2010-April 2011

\begin{tabular}{|c|c|c|c|c|c|c|c|c|}
\hline & \multicolumn{4}{|c|}{ Boys } & \multicolumn{4}{|c|}{ Girls } \\
\hline & RDA & Mean & SE & Median & RDA & Mean & SE & Median \\
\hline Energy (kJ) & 7531 & 8644 & 174.5 & 8502 & $6694-7531$ & 8912 & $169 \cdot 9$ & 8690 \\
\hline Energy (kcal) & 1800 & 2066 & 41.7 & 2032 & $1600-1800$ & 2130 & 40.6 & 2077 \\
\hline Carbohydrates (g) & 130 & 286.7 & $6 \cdot 0$ & 279.2 & 130 & 298.9 & 5.9 & $297 \cdot 3$ \\
\hline Protein $(\mathrm{g})$ & 34 & $71 \cdot 2$ & 1.7 & $68 \cdot 2$ & 34 & $73 \cdot 0$ & $1 \cdot 7$ & $72 \cdot 6$ \\
\hline Fat $(\mathrm{g})$ & $25-35$ & $72 \cdot 7$ & 1.8 & 68.3 & $25-35$ & $73 \cdot 7$ & 1.8 & 71.9 \\
\hline Saturated fat $(\mathrm{g})$ & - & $24 \cdot 3$ & 0.7 & 23.8 & $<10$ & 24.6 & 0.7 & $23 \cdot 4$ \\
\hline Trans fat $(\mathrm{g})$ & - & 0.6 & 0.1 & 0.3 & - & 0.7 & 0.1 & 0.4 \\
\hline Cholesterol (mg) & $<300$ & $248 \cdot 6$ & $10 \cdot 0$ & 230.4 & $<300$ & 249.4 & $10 \cdot 6$ & $206 \cdot 1$ \\
\hline Sugar (g) & - & $127 \cdot 7^{*}$ & 3.6 & 123.5 & - & $139 \cdot 1$ & 3.7 & $135 \cdot 1$ \\
\hline Fibre $(\mathrm{g})$ & 25 & $14 \cdot 0$ & 0.4 & $12 \cdot 6$ & 22 & 14.6 & 0.4 & 13.5 \\
\hline Vitamin A (RE) & 600 & $490 \cdot 2$ & $35 \cdot 8$ & 331.6 & 600 & 565.4 & $46 \cdot 8$ & 371.8 \\
\hline Vitamin C (mg) & 45 & $96 \cdot 3$ & 5.5 & 87.4 & 45 & 108.0 & $16 \cdot 2$ & 81.5 \\
\hline Vitamin D $(\mu \mathrm{g})$ & 15 & 1.3 & 0.1 & 0.9 & 15 & 1.5 & 0.1 & 1.2 \\
\hline $\mathrm{Na}(\mathrm{mg})$ & $<2200$ & 2723.0 & 67.5 & $2604 \cdot 4$ & $<2200$ & 2688.5 & 63.5 & $2662 \cdot 4$ \\
\hline $\mathrm{Ca}(\mathrm{mg})$ & $<1300$ & $581 \cdot 2$ & 18.4 & 544.9 & 1300 & 610.5 & 31.3 & $569 \cdot 0$ \\
\hline $\mathrm{Fe}(\mathrm{mg})$ & 8 & $12 \cdot 2$ & 0.3 & 11.5 & 8 & $12 \cdot 2$ & 0.3 & 11.4 \\
\hline$\%$ Energy from carbohydrate & $45-65$ & 55.7 & 0.5 & $56 \cdot 1$ & $45-65$ & $56 \cdot 3$ & 0.5 & $56 \cdot 4$ \\
\hline$\%$ Energy from protein & $10-30$ & $13 \cdot 8$ & 0.2 & $13 \cdot 6$ & $10-30$ & 13.7 & 0.2 & 13.5 \\
\hline$\%$ Energy from fat & $25-35$ & 31.4 & 0.3 & $31 \cdot 3$ & $25-35$ & $30 \cdot 9$ & 0.4 & $30 \cdot 7$ \\
\hline$\%$ Energy from saturated fat & $<10$ & 10.5 & 0.2 & $10 \cdot 4$ & $<10$ & $10 \cdot 2$ & 0.2 & $10 \cdot 1$ \\
\hline$\%$ Energy from trans fat & - & 0.3 & 0.0 & 0.1 & - & 0.3 & 0.0 & 0.2 \\
\hline$\%$ Energy from sugar & - & $24 \cdot 6$ & 0.5 & $24 \cdot 1$ & - & $26 \cdot 1$ & 0.5 & $26 \cdot 0$ \\
\hline$\%$ Energy from added sugar & - & $18 \cdot 1$ & 0.5 & 18.0 & - & 19.7 & 0.5 & $19 \cdot 7$ \\
\hline$\%$ Energy from empty-calorie foods & - & $11 \cdot 3$ & 0.5 & $10 \cdot 9$ & - & 11.7 & 0.5 & $11 \cdot 2$ \\
\hline$\%$ Energy from empty-calorie sugar-added beverages & - & 8.8 & 0.5 & $8 \cdot 1$ & - & 8.9 & 0.5 & 7.9 \\
\hline
\end{tabular}

Mean intake of boys significantly different from that of girls: ${ }^{\star} P<0.05$.

(boys, $56 \cdot 6$ (se 0.65); girls, $58 \cdot 3$ (se 0.61); $P=0.058$ ), overall balance (boys, 1.28 (se 0.14); girls, 1.65 (SE 0.14); $P=0 \cdot 068)$ and macronutrient ratios (boys, 1.02 (SE 0.12); girls, 1.37 (SE 0.13); $P=0 \cdot 054$; data not shown). Girls also consumed significantly more vegetables (boys, 1.81 (SE 0.10); girls, $2 \cdot 12$ (SE 0.09); $P=0.026$ ) and vitamin C (boys, 4.61 (SE 0.07); girls, 4.78 (se 0.05); $P=0.050$ ) than boys. There were no significant differences in overall diet quality nor its components by weight status. Na intake was significantly higher among children from two-parent households (data not shown).

\section{Models for identification of children at risk of excess energy intake}

The penalized logistic model

The variables selected from the LASSO regression are described in Table 4 where each row represents the value taken by a different coefficient. From the log-likelihood ratio $\chi^{2}$ test, the model's $\chi^{2}\left(L^{2}\right)$ value was 212.44 with Prob $>\chi^{2}=0 \cdot 001$.

Table 5 presents significant OR for the likelihood of excess energy intake by sociodemographic factors and DQI-I sub-components. Girls were more likely to consume excess energy intake compared with boys. Children from two-parent households showed decreased likelihood of high energy intake compared with those from singleparent households. Children who reported a variety of food groups were less likely to consume excess energy and the likelihood decreased with fewer food groups omitted in the diet. More vegetables and fruits and lower percentage energy contribution from empty calories were inversely related to excess energy intake. Intake of more than $2400 \mathrm{mg} \mathrm{Na} / \mathrm{d}$ and higher macronutrient and fatty acid ratios were positively associated with the consumption of excess energy. In some cases, differences in OR from one category to the next were low. For example, for food group variety, 'greater than 3 food groups missing $(\mathrm{OR}=0.003 ; 95 \%$ CI 0.0002, 0.04)' had as negative an effect as did 'greater than 4 groups missing' and shows that the this category did not confer a practical difference in risk compared with the reference.

\section{Marginal effects}

The MEM for all significant, discrete and continuous covariates in our selected models were calculated. The marginal effect is an instantaneous effect that a change in a particular explanatory variable has on the predictive probability of a quantity, when the other covariates are kept fixed. In our case, we were therefore able to assess the effect of a change from one category of a particular variable, such as empty calorie intake, on the likelihood of a child to have membership in the excess energy intake group.

The MEM for empty calorie intake was $-0 \cdot 17$ and shows that for a student with all other average values, held 
Table 3 Components of the Diet Quality Index-International (DQI-I) and the percentage in component sub-categories among children aged $9-10$ years ( $n$ 362), Barbados Children's Health and Nutrition Study (BCHNS), September 2010-April 2011

\begin{tabular}{|c|c|c|}
\hline $\begin{array}{l}\text { Component (range } \\
\text { of score) }\end{array}$ & Scoring criteria & $\frac{\text { All (362) }}{\%}$ \\
\hline \multirow{2}{*}{\multicolumn{3}{|c|}{$\begin{array}{l}\text { DQI-I total }(0-100) \\
\text { Variety }(0-20)\end{array}$}} \\
\hline & & \\
\hline \multirow[t]{6}{*}{$\begin{array}{l}\text { Food group } \\
\text { variety }(0-15)\end{array}$} & $\begin{array}{l}\geq 1 \text { serving from each food } \\
\text { group/d = 15 }\end{array}$ & $24 \cdot 3$ \\
\hline & $\begin{array}{l}\text { Any } 1 \text { food group missing/ } \\
\qquad d=12\end{array}$ & $36 \cdot 5$ \\
\hline & $\begin{array}{l}\text { Any } 2 \text { food groups missing/ } \\
\quad d=9\end{array}$ & $27 \cdot 1$ \\
\hline & $\begin{array}{l}\text { Any } 3 \text { food groups missing/ } \\
\quad d=6\end{array}$ & $11 \cdot 3$ \\
\hline & $\geq 4$ food groups missing $/ d=3$ & 0.8 \\
\hline & None from any food groups & 0.0 \\
\hline \multirow{4}{*}{$\begin{array}{l}\text { Variety for protein } \\
\text { source }(0-5)\end{array}$} & $\geq 3$ different sources $/ d=5$ & $57 \cdot 2$ \\
\hline & 2 different sources $/ \mathrm{d}=3$ & $27 \cdot 9$ \\
\hline & From 1 source/d=1 & $14 \cdot 1$ \\
\hline & None & 0.8 \\
\hline \multicolumn{3}{|l|}{ Adequacy (0-40) } \\
\hline \multirow[t]{4}{*}{$\begin{array}{l}\text { Vegetable group } \\
(0-5)\end{array}$} & $\begin{array}{l}\geq 3-5 \text { servings } / d=5 \\
0 \text { servings } / d=0\end{array}$ & \\
\hline & $\geq 100 \%$ & $4 \cdot 7$ \\
\hline & $<100-50 \%$ & $26 \cdot 2$ \\
\hline & $<50 \%$ & $69 \cdot 0$ \\
\hline \multirow[t]{4}{*}{ Fruit group (0-5) } & $\begin{array}{l}\geq 2-4 \text { servings } / d=5 \\
0 \text { servings } / d=0\end{array}$ & \\
\hline & $\geq 100 \%$ & $15 \cdot 7$ \\
\hline & $<100-50 \%$ & $25 \cdot 4$ \\
\hline & $<50 \%$ & $58 \cdot 8$ \\
\hline \multirow[t]{4}{*}{ Grain group $(0-5)$} & $\begin{array}{l}\geq 6-11 \text { servings } / d=5 \\
0 \text { servings } / d=0\end{array}$ & \\
\hline & $\geq 100 \%$ & $35 \cdot 9$ \\
\hline & $<100-50 \%$ & 58.5 \\
\hline & $<50 \%$ & $5 \cdot 4$ \\
\hline \multirow[t]{3}{*}{ Fibre (0-5) } & $\geq 20-30 \mathrm{~g} / \mathrm{d}=5,0 \mathrm{~g} / \mathrm{d}=0$ & \\
\hline & $\begin{array}{l}\geq 100 \% \\
<100-50 \%\end{array}$ & $\begin{array}{r}3 \cdot 3 \\
60 \cdot 7\end{array}$ \\
\hline & $<50 \%$ & $35 \cdot 9$ \\
\hline \multirow[t]{4}{*}{ Protein (0-5) } & $\begin{array}{c}\geq 10 \% \text { of energy } / d=5 \\
0 \% \text { of energy } / d=0\end{array}$ & \\
\hline & $\geq 100 \%$ & 94.5 \\
\hline & $<100-50 \%$ & $5 \cdot 2$ \\
\hline & $<50 \%$ & 0.2 \\
\hline \multirow[t]{4}{*}{ Iron $(0-5)$} & $\begin{array}{c}\geq 100 \% \operatorname{RDA}(\mathrm{Al}) / \mathrm{d}=5 \\
0 \% \operatorname{RDA}(\mathrm{Al}) / \mathrm{d}=0\end{array}$ & \\
\hline & $\geq 100 \%$ & $88 \cdot 1$ \\
\hline & $<100-50 \%$ & $11 \cdot 3$ \\
\hline & $<50 \%$ & 0.5 \\
\hline \multirow[t]{4}{*}{ Calcium (0-5) } & $\begin{array}{c}\geq 100 \% \operatorname{RDA}(\mathrm{Al}) / \mathrm{d}=5 \\
0 \% \operatorname{RDA}(\mathrm{Al}) / \mathrm{d}=0\end{array}$ & \\
\hline & $\geq 100 \%$ & 1.4 \\
\hline & $<100-50 \%$ & $32 \cdot 3$ \\
\hline & $<50 \%$ & $66 \cdot 2$ \\
\hline \multirow[t]{4}{*}{ Vitamin C (0-5) } & $\begin{array}{c}\geq 100 \% \text { RDA }(\mathrm{RNI}) / \mathrm{d}=5 \\
0 \% \operatorname{RDA}(\mathrm{RNI}) / \mathrm{d}=0\end{array}$ & \\
\hline & $\geq 100 \%$ & $84 \cdot 0$ \\
\hline & $<100-50 \%$ & $10 \cdot 7$ \\
\hline & $<50 \%$ & $5 \cdot 2$ \\
\hline \multicolumn{3}{|l|}{ Moderation (0-30) } \\
\hline \multirow[t]{2}{*}{ Total fat $(0-6)$} & $\begin{array}{l}\leq 20 \% \text { of total energy } / d=6 \\
>20-30 \% \text { of total energy } / \\
d=3\end{array}$ & $\begin{array}{r}1 \cdot 7 \\
37 \cdot 8\end{array}$ \\
\hline & $>30 \%$ of total energy $/ d=0$ & $60 \cdot 5$ \\
\hline \multirow{3}{*}{$\begin{array}{l}\text { Saturated fat } \\
\quad(0-6)\end{array}$} & $\leq 7 \%$ of total energy/d $=6$ & $7 \cdot 7$ \\
\hline & $>7-10 \%$ of total energy $/ \mathrm{d}=3$ & 38.4 \\
\hline & $>10 \%$ of total energy $/ \mathrm{d}=0$ & $53 \cdot 9$ \\
\hline
\end{tabular}

Table 3 Continued

\begin{tabular}{|c|c|c|}
\hline \multirow{2}{*}{$\begin{array}{l}\text { Component (range } \\
\text { of score) }\end{array}$} & \multirow[b]{2}{*}{ Scoring criteria } & \multirow{2}{*}{$\frac{\text { All (362) }}{\%}$} \\
\hline & & \\
\hline \multirow[t]{3}{*}{ Cholesterol (0-6) } & $\leq 300 \mathrm{mg} / \mathrm{d}=6$ & $72 \cdot 4$ \\
\hline & $>300 \mathrm{mg} / \mathrm{d}=3$ & $14 \cdot 1$ \\
\hline & $>400 \mathrm{mg} / \mathrm{d}=0$ & 13.5 \\
\hline \multirow[t]{3}{*}{ Sodium (0-6) } & $\leq 2400 \mathrm{mg} / \mathrm{d}=6$ & 39.5 \\
\hline & $>2400-3400 \mathrm{mg} / \mathrm{d}=3$ & $41 \cdot 2$ \\
\hline & $>3400 \mathrm{mg} / \mathrm{d}=0$ & $19 \cdot 3$ \\
\hline \multirow{3}{*}{$\begin{array}{l}\text { Empty-calorie } \\
\text { foods }(0-6)\end{array}$} & $\leq 3 \%$ of total energy $/ \mathrm{d}=6$ & 8.6 \\
\hline & $>3-10 \%$ of total energy $/ \mathrm{d}=3$ & $36 \cdot 2$ \\
\hline & $>10 \%$ of total energy/d $=0$ & $55 \cdot 2$ \\
\hline \multicolumn{3}{|l|}{$\begin{array}{l}\text { Overall balance } \\
\quad(0-10)\end{array}$} \\
\hline \multirow{4}{*}{$\begin{array}{l}\text { Macronutrient } \\
\text { ratio } \\
\text { (carbohydrate: } \\
\text { protein:fat) } \\
\text { (0-6) }\end{array}$} & $55-65: 10-15: 15-25=6$ & $4 \cdot 1$ \\
\hline & $52-68: 9-16: 13-27=4$ & $12 \cdot 7$ \\
\hline & $50-70: 8-17: 12-30=2$ & $22 \cdot 4$ \\
\hline & Otherwise $=0$ & $60 \cdot 8$ \\
\hline \multirow[t]{3}{*}{$\begin{array}{l}\text { Fatty acid ratio } \\
\quad(0-4)\end{array}$} & $\begin{array}{c}\mathrm{P} / \mathrm{S}=1-1.5 \text { and } \mathrm{M} / \mathrm{S}=1- \\
\quad 1.5=4\end{array}$ & $3 \cdot 3$ \\
\hline & $\begin{array}{l}\text { Else } P / S=0.8-1.7 \text { and } \\
M / S=0.8-1.7=2\end{array}$ & $6 \cdot 6$ \\
\hline & Otherwise $=0$ & $90 \cdot 1$ \\
\hline
\end{tabular}

Al, Adequate intake; RNI, Reference Nutrient Intake; P/S, polyunsaturated/ saturated; $\mathrm{M} / \mathrm{S}$, monounsaturated/saturated.

constant, the predictive probability of entering the excess energy intake category increases by $29 \%$ as s/he moves from an empty calorie score of 3 to 6. Similarly, the MEM for DQI-I fruit intake score of -0.03 reveals that for an increase of one unit in fruit intake, the probability of excess energy intake was 1.84 times lower. The MEM for the DQI-I vegetable and iron scores were -0.08 and 0.25 , respectively (data not shown).

The data showed that as students' intake of empty calories increased, $\mathrm{Na}$ intake also increased, as did the probability that the student would be in the excess energy intake group.

The parsimonious model attained an overall rate of correct classification estimated at $86.4 \%$, with $91 \cdot 1 \%$ sensitivity and $76 \cdot 8 \%$ specificity.

\section{Practical model}

Our most parsimonious model included seven of the seventeen subcomponents. Four of these sub-components, namely sodium, iron, macronutrient ratio and fatty acid ratio (nuisance covariates), would be difficult to estimate from a brief interview. Therefore, we created ten further models all nested in our parsimonious model; one containing none of the listed nuisance covariates. The predictors were overall food group variety, variety from protein, vegetables, fruits and empty calorie intake.

Our multilevel model to further examine the relationship of empty calories (moderation category) with total energy intake showed a linear relationship. Each 29.1 unit increase in empty calories was associated with an increase of $4 \cdot 18 \mathrm{~kJ}$ ( $1 \mathrm{kcal})$ in total energy intake (data not shown). 
Table 4 The variables selected from the LASSO regression and corresponding coefficients for predicting excess energy intake among children aged $9-10$ years $(n$ 362), Barbados Children's Health and Nutrition Study (BCHNS), September 2010-April 2011

\begin{tabular}{lr}
\hline Variable & Coefficient \\
\hline Sex & 0.115 \\
Household type & -0.206 \\
Overall food group variety & 0.044 \\
Variety for protein source & 0.0415 \\
Vegetable group & -0.029 \\
Fruit group & -0.024 \\
Grain group & -0.011 \\
Protein & -0.173 \\
Iron & 0.197 \\
Calcium & 0.009 \\
Vitamin C & 0.037 \\
Sodium & -0.075 \\
Empty-calorie foods & -0.037 \\
Macronutrient ratio & 0.015 \\
Fatty acid ratio & 0.032 \\
\hline
\end{tabular}

LASSO, least absolute shrinkage and selection operator.

Each row represents the value taken by a different coefficient. Variables that enter the proposed model early show the most predictive ability, whereas variables that enter late show less.

\section{Discussion}

The current study adds to the few data that provide detailed descriptions of dietary intakes and diet quality among children. We found that on average, energy intake exceeded the RDA and the consumption of fruits, vegetables, $\mathrm{Ca}$ and fibre were low whereas intakes of fats and empty-calorie foods were high. The overall score for diet quality of 57.5 was modest ${ }^{(18)}$. Our practical model to identify children consuming excess energy suggested the model could correctly classify $82.3 \%$ of children.

Compared with maximum possible scores, the scores for adequacy (28/40) and variety (15/20) were high, reflective of the high food availability and by extension food security ${ }^{(23)}$. The lower moderation $(12 \cdot 8 / 30)$ and very poor overall balance $(1 \cdot 4 / 10)$ scores are suggestive of developed-country patterns of overnutrition ${ }^{(24)}$.

While the overall scores for diet quality and its main categories were relatively good and in keeping with world data $^{(18)}$, there are key areas of concern. Most of the children reported higher than recommended levels of energy intake. Both fat and sugar intakes were high and similar to our previous finding ${ }^{(12)}$ that children's energy intake from sugar was $25 \%$. In the present study, $11 \%$ of energy was empty calories and 9\% was empty calories from sugaradded beverages, which was considerably higher than reported for Canadian children aged 8-10 years whose energy intake from sugar was $12 \%$ with $2 \cdot 6 \%$ from sugaradded beverages ${ }^{(5)}$. Given that with almost one-fifth (18.9\%) of energy was from added sugar but only $11 \%$ was from empty-calorie foods, this indicates that a considerable amount of sugar intake was concentrated in foods that also deliver important nutrients such as flavoured milks. Our findings suggest that targeting the consumption of all foods containing sugar and not only empty-calorie beverages may be more important for obesity prevention and management.

Ca intake was very low. Sixty-six per cent of children reported intakes below the US Department of Agriculture recommendations. Of note, 9-10-year-olds are approaching or in early puberty, hence requirements for Ca are high due to increased rates of growth ${ }^{(25)}$. Given the culturally embedded practice of high sugar consumption with milk, the question arises as to whether local recommendations should promote increased intake of Ca from milk. Thus, consideration should be given to alternatives such as leafy greens, seafood (including canned fish), legumes and fortified foods as recommendations for increased intake of $\mathrm{Ca}$.

There were few differences in diet quality by sex, weight status group or household type. The absence of differences by these factors is not surprising given the large middle class and epidemiological transition ${ }^{(26)}$. Further study on the distribution of food-related chronic disease markers in childhood is an important precondition for identification of targeted interventions.

The current study shows that girls were more likely to consume excess energy and showed higher prevalence of overweight than boys. The current findings, similar to those from previous studies, point to a need for overweight/obesity interventions with a particular focus on girls $^{(13,15,27)}$. On the other hand, girls enter puberty at an earlier stage than boys so increased energy consumption may reflect increased needs.

Children with low moderation scores $(\leq 12 / 30$ DQI-I points) were more likely consume excess energy. Macronutrients and components of the moderation category (empty-calorie foods and sodium) were positively related to excess energy intake.

Our multilevel model of total energy intake showed that there was little practical relationship between energy intake and the proportion of empty calories a child consumed, suggesting that the children across all ranges of energy intake ate similar quality food with respect to energy density. This means that even those whose energy consumption was within the recommended ranges may still be at increased risk related to pathogenic constituents of the diet such as sugar. A diet that provides high energy from sugar is thought to potentiate diabetes via the fructose route ${ }^{(28)}$. This is important given the high levels of diabetes in the adult population ${ }^{(29)}$, who most likely have diets similar to children ${ }^{(12)}$. Large portions are therefore likely to be an important contributor to additional metabolic risk for this group since most children overshoot their energy recommendations.

Given the established association between SES and consumption of energy-dense, low-nutrient foods, it is important for the relationship of SES with diet quality be further explored in Barbados. Studies show that children living in female-headed homes ${ }^{(30)}$ or multigenerational 
Table $5 \mathrm{OR}$ and $95 \% \mathrm{Cl}$ for the likelihood of excess energy intake by sociodemographic factors and Diet Quality IndexInternational (DQI-I) sub-components among children aged 9-10 years ( $n$ 362), Barbados Children's Health and Nutrition Study (BCHNS), September 2010-April 2011

\begin{tabular}{|c|c|c|c|}
\hline Variable† & OR & $95 \% \mathrm{Cl}$ & $P$ \\
\hline \multicolumn{4}{|l|}{ Gender } \\
\hline Boys & 1.00 & Reference & \\
\hline Girls & $6 \cdot 42$ & $2 \cdot 49,16.52$ & 0.001 \\
\hline \multicolumn{4}{|l|}{ Household type } \\
\hline Single-parent & 1.00 & Reference & \\
\hline Two-parent & 0.15 & $0.02,0.93$ & 0.042 \\
\hline \multicolumn{4}{|l|}{ Overall food group variety } \\
\hline$\geq 4$ food groups missing/d (3 points) & 1.00 & Reference & \\
\hline Any 3 food groups missing/d (6 points) & 0.003 & $0.0002,0.04$ & \\
\hline Any 2 food groups missing/d (9 points) & 0.03 & $0.004,0.21$ & 0.001 \\
\hline \multicolumn{4}{|l|}{ Variety for protein source } \\
\hline 1 source/d (1 point) & 1.00 & Reference & \\
\hline$>1$ source/d & 0.23 & $0.05,0.91$ & 0.036 \\
\hline \multicolumn{4}{|l|}{ Vegetables } \\
\hline $0-2$ servings/d ( $\leq 2.5$ points) & 1.00 & Reference & \\
\hline $3-5$ servings/d (5 points) & 0.48 & $0.31,0.75$ & 0.001 \\
\hline \multicolumn{4}{|l|}{ Fruits } \\
\hline $0-2$ servings /d ( $\leq 2.5$ points $)$ & 1.00 & Reference & \\
\hline $2-4$ servings/d (5 points) & 0.55 & $0.39,0.80$ & 0.002 \\
\hline \multicolumn{4}{|l|}{ Sodium } \\
\hline$\leq 2400 \mathrm{mg} / \mathrm{d}$ (6 points) & 1.00 & Reference & \\
\hline > 2400-3400 mg/d (3 points) & $27 \cdot 98$ & $9 \cdot 11,85.89$ & 0.001 \\
\hline \multicolumn{4}{|l|}{ Empty-calorie foods } \\
\hline$>10 \%$ of total energy/d (0 point) & 1.00 & Reference & \\
\hline$>3-10 \%$ of total energy/d (3 points) & 0.25 & $0.90,0.72$ & 0.01 \\
\hline$\leq 3 \%$ of total energy/d ( 6 points) & 0.07 & $0.14,0.33$ & 0.001 \\
\hline \multicolumn{4}{|l|}{ Macronutrient ratio (carbohydrate:protein:fat) } \\
\hline Otherwise (0 point) & 1.00 & Reference & \\
\hline 52-68:9-16:13-27 (4 points) & $5 \cdot 80$ & $1 \cdot 15,29 \cdot 17$ & 0.033 \\
\hline \multicolumn{4}{|l|}{ Fatty acid ratio } \\
\hline Otherwise ( 0 point) & 1.00 & Reference & \\
\hline $\mathrm{P} / \mathrm{S}=1-1.5$ and $\mathrm{M} / \mathrm{S}=1-1.5$ (4 points) & 9.07 & $1 \cdot 25,65 \cdot 71$ & 0.029 \\
\hline
\end{tabular}

$\mathrm{P} / \mathrm{S}$, polyunsaturated/saturated; M/S, monounsaturated/saturated.

OR and $95 \% \mathrm{Cl}$ for significant DQI-I components from binary logistic regression of reported energy intake (recommended $v$. excess). The Hosmer-Lemeshow test was used to judge model fit. Predictive probabilities of all significant independent variables were interpreted using marginal effects at the means.

†The model was adjusted for age, sex, household type (single- or two-parent household) and BMI Z-scores.

households $^{(31)}$ were more likely to face socio-economic disadvantage compared with those from two-parent homes ${ }^{(32)}$. Choi and Marks highlight that marital relationships may provide a buffer against the adverse effects of lower SES, including social support, social control and financial resources ${ }^{(33)}$. Our data indicate that the gradient based on household type, our proxy for SES, was negligible in practical terms. This may be an effect of the broad middle class and high food availability. This feeds into one of our aims to find culturally sensitive methods of identifying children at increased metabolic risk.

Items such as percentage of protein or macronutrient ratio did not contribute significantly to variance of predictors of energy intake and may be related to the high DQI-I score (95\% of children met protein requirements). Protein and macronutrients are therefore not useful in identifying children at increased risk of high energy intake since they are replete across the range of the population.

Cultural practices including food behaviours are expected to travel with migrants to their new homes. Tull and Taylor showed an independent association of place of birth with the frequency of fast-food restaurant use among
Afro-Caribbean US residents ${ }^{(34)}$. Our findings are hence also important for countries that have substantial Caribbean immigrant populations such as the USA and the UK.

We have presented here a practical model that would require information on only five of the DQI-I sub-components (overall food group variety, variety for protein source, fruits, vegetables and empty calorie intake) to examine excess energy intake in children and thereby those at increased food-related risk of obesity and chronic disease. This tool must be tested in a larger sample to ensure its external validity. The model may be useful in settings similar to ours.

\section{Strengths and limitations}

We are aware of the limitations of a small data set with respect to developing robust findings for a methodology to identify children at risk of excess energy intake. Nevertheless, the methodology presented here can be applied to a larger data set where energy intake is estimated for a group by more precise means such as doubly labelled 
water or accelerometery coupled with resting metabolic rate. We acknowledge that energy expenditure would reduce the effect of high energy intake. However, it is unlikely that most children consuming excessive energy compensate for this by high active energy expenditure.

Our cohort's age was narrow (9-10 years). We therefore did not expect age to be a significant covariate, but we nevertheless entered it as one of the initial covariates in the LASSO regression. This narrow age band would also correspond to a limited range regarding pubertal status for which age was our proxy.

In the current study we used three $24 \mathrm{~h}$ recalls, representing two weekdays and one weekend day, rather than a single recall or use of food frequencies, in order to reduce recall bias ${ }^{(35)}$ and increase the likelihood of being representative of usual intake. This increases the generalizability of usual eating patterns. We are aware of the limitation of using $24 \mathrm{~h}$ recalls; however, this are the most commonly used method of dietary data collection through self-report $^{(36)}$ and has been shown to be more accurate when it is closer in time to the interview. As such, children aged 8 years or older have been shown to adequately report $24 \mathrm{~h}$ dietary intakes ${ }^{(37)}$. Importantly, all dietary intake methods have limitations with regard to measuring exact nutrient intake but can be useful in ranking children with respect to intake ${ }^{(35)}$ and in describing dietary patterns $^{(38)}$.

We used the DQI-I, which inherently controls for energy intake, to compare the quality of diets in different groups over all ranges of dietary intake in the absence of energy expenditure data. The DQI-I has the advantage of evaluating the relative intake of foods low in nutrient density and specifically empty calories, which have implications for the development of overweight and concomitant chronic diseases ${ }^{(18)}$. Current findings on the usefulness of dietary diversity as a measure of diet quality are mixed ${ }^{(39)}$ particularly among children ${ }^{(40,41)}$. We therefore included dietary diversity as a measure of high diet quality as was traditionally done and found children's diets were in keeping with assessment of dietary intakes conducted among adults in this same Barbadian population $^{(42)}$.

We used household status as a proxy for SES in the absence of parents' information. We recognize that this is one component of SES, but among children it is likely to be very important given that parental financial status would be a major determinant for children's SES. There is evidence $^{(30-32)}$ that indicates that children from singleparent or multigenerational homes are generally more deprived than children from two-parent homes.

Our data represent a randomly selected subset of a representative sample ${ }^{(10)}$. The good fit model suggests that our model would be suitable for use in similar populations. Although the response rate for the original study was $56 \%$, among children who returned consent forms, 99\% were positive. The most common reason for non- participation was that children forgot to take consent forms to parents. It should also be borne in mind that all schools that were approached participated.

We have shown high dietary adequacy and variety with few differences in diet quality by sex, weight status or household type, despite high energy intake and low intakes of fruit and vegetables. Based mostly on developed-country data, empty calories from sugary drinks are a major focus of obesity interventions for children. Our findings suggest that greater emphasis should be placed upon excess energy intake resulting from large portion size. This may also be an important target for countries with appreciable numbers of Caribbean migrants. Our practical model therefore provides a useful tool for identification of children from easily captured elements of the diet that predict a propensity to consume greater amounts of energy than recommended. This is important as it can be used as a screening tool for intervention early in the life cycle when physical measures such as overweight or elevated blood pressure would lack sensitivity. These data also form a basis for further, more in-depth studies in the arena.

\section{Conclusions}

Children's diets were varied despite low intakes of fruits and vegetables. Levels of obesity were high, and children were at increased risk primarily due to large portion size and high energy intake from sugar. Children at increased risk could not be identified by weight status factors. A practical model including five of the DQI-I components (overall food group variety, variety for protein source, fruits, vegetables and empty calorie intake) can be used to identify children at risk of excess energy intake. This tool should be tested in an external sample.

\section{Acknowledgements}

Acknowledgements: The authors wish to thank JaDon Knight, Melissa Fernandez, Kimberly Rudder and JasonAnthony Gaskin. Financial support: This work was supported by a grant from the Campus Research Awards Committee in the Department of Graduate Studies at the University of the West Indies in 2010. The Campus Research Awards Committee had no role in the design, analysis or writing of the manuscript. Conflict of interest: None. Authorship: P.S.G. wrote the first draft of the manuscript and was involved in its conception, design and analysis, as well as final approval. P.C., B.S., H.B. and P.S.G. were responsible for analyses. M.D.J. and J.W. reviewed the manuscript and revised it critically for intellectual content. O.G.B.S. was responsible for data capture, collation and cleaning. All authors gave approval of the final manuscript. Ethics of buman subject participation: 
This study was conducted according to the guidelines laid down in the Declaration of Helsinki and all procedures involving human subjects were approved by the Institutional Review Board of the University of the West Indies/ Ministry of Health Barbados. Informed written consent was obtained from parents and assent from children.

\section{References}

1. Nicklas TA, O'Neil CE \& Fulgoni VL (2012) Diet quality is inversely related to cardiovascular risk factors in adults. $J$ Nutr 142, 2112-2118.

2. Jennings A, Welch A, van Sluijs EM et al. (2011) Diet quality is independently associated with weight status in children aged 9-10 years. J Nutr 141, 453-459.

3. Poti JM, Slining MM \& Popkin BM (2014) Where are kids getting their empty calories? Stores, schools, and fast-food restaurants each played an important role in empty calorie intake among US children during 2009-2010. J Acad Nutr Diet 114, 908-917.

4. Poti JM, Duffey KJ \& Popkin BM (2014) The association of fast food consumption with poor dietary outcomes and obesity among children: is it the fast food or the remainder of the diet? Am J Clin Nutr 99, 162-171.

5. Wang J, Shang L, Light K et al. (2015) Associations between added sugar (solid vs. liquid) intakes, diet quality and adiposity indicators in Canadian children. Appl Physiol Nutr Metab 40, 835-841.

6. O'Neil CE, Nicklas TA \& Fulgoni VL (2015) Consumption of apples is associated with a better diet quality and reduced risk of obesity in children: National Health and Nutrition Examination Survey (NHANES) 2003-2010. Nutr J 14, 48.

7. Fulgoni VL III, Nicklas TA \& O'Neil CE (2012) Mango consumption is associated with better diet quality and increased nutrient intakes in adult participants from the National Health and Nutrition Examination Survey (2001-2008). FASEB J 26, 239.233.

8. Ramdath DD, Simeon D, Wong M et al. (1995) Iron status of schoolchildren with varying intensities of Trichuris trichiura infection. Parasitology 110, 347-351.

9. Gaskin PS, Nielsen AL, Willie D et al. (2014) Early childhood nutritional status in CARICOM countries: an overview with respect to five nutrition related millennium development goals. J Environ Public Health 2014, 580928.

10. Gaskin PS, Hall RV, Chami P et al. (2015) Associations of blood pressure with body composition among AfroCaribbean children in Barbados. PLoS One 10, e0121107.

11. Imamura F, Micha R, Khatibzadeh $S$ et al. (2015) Dietary quality among men and women in 187 countries in 1990 and 2010: a systematic assessment. Lancet Glob Health 3, e132-e142.

12. Gaskin PS, Lai P, Guy D et al. (2012) Diet, physical activity, weight status, and culture in a sample of children from the developing world. J Nutr Metab 2012, 242875.

13. Fernandez MA, Kubow S, Gray-Donald K et al. (2015) Drastic increases in overweight and obesity from 1981 to 2010 and related risk factors: results from the Barbados Children's Health and Nutrition Study. Public Health Nutr 18, 3070-3077.

14. Ranjit N, Wilkinson AV, Lytle LM et al. (2015) Socioeconomic inequalities in children's diet: the role of the home food environment. Int J Behav Nutr Phys Act 12, Suppl. 1, S4.

15. Gaskin PS, Broome H, Alert C et al. (2008) Misperceptions, inactivity and maternal factors may drive obesity among Barbadian adolescents. Public Health Nutr 11, 41-48.
16. McLaren L (2007) Socioeconomic status and obesity. Epidemiol Rev 29, 29-48.

17. Tull ES, Ambrose JJ \& Chambers E (2003) A preliminary assessment of acculturation and its relationship to body size and glucose intolerance among blacks in the US Virgin Islands. Ethn Dis 13, 15-21.

18. Kim S, Haines PS, Siega-Riz AM et al. (2003) The Diet Quality Index-International (DQI-I) provides an effective tool for cross-national comparison of diet quality as illustrated by China and the United States. J Nutr 133, 3476-3484.

19. World Health Organization (2011) Steps in applying probability proportional to size (PPS) sampling. Tuberculosis Prevalence Surveys: A Handbook, 2nd ed., pp. 75-77. Geneva: WHO.

20. McDowell MA, Fryar CD, Ogden CL et al. (2008) Anthropometric reference data for children and adults: United States, 2003-2006. Natl Health Stat Report issue 10, 1-48.

21. Onis Md, Onyango AW, Borghi E et al. (2007) Development of a WHO growth reference for school-aged children and adolescents. Bull World Health Organ 85, 660-667.

22. McGuire S (2011) US Department of Agriculture and US Department of Health and Human Services, Dietary Guidelines for Americans, 2010. Washington, DC: US Government Printing Office, January 2011. Adv Nutr 2, 293-294.

23. Yu B, You L \& Fan S (2010) Toward a Typology of Food Security in Developing Countries. Washington, DC: International Food Policy Research Institute.

24. Carlson A, Lino M, Gerrior S et al. (2003) Report card on the diet quality of children ages 2 to 9. Fam Econ Nutr Rev 15, 52.

25. Anderson JJ (2001) Calcium requirements during adolescence to maximize bone health. J Am Coll Nutr 20, 2 Suppl., 186S-191S

26. Gribble JN \& Preston SH (1993) The Epidemiological Transition: Policy and Planning Implications for Developing Countries. Washington, DC: National Academies Press.

27. Gaskin PS, Lai P, Guy D et al. (2012) Diet, physical activity, weight status, and culture in a sample of children from the developing world. J Nutr Metab 2012, 242875.

28. Gugliucci A (2016) Fructose surges damage hepatic adenosyl-monophosphate-dependent kinase and lead to increased lipogenesis and hepatic insulin resistance. Med Hypotheses 93, 87-92.

29. Leske MC, Wu S-Y, Hennis A et al. (1999) Diabetes, hypertension, and central obesity as cataract risk factors in a black population: the Barbados Eye Study1. Ophthalmology 106, 35-41.

30. Stuart S (1996) Female-headed families: a comparative perspective of the Caribbean and the developed world. Gend Dev 4, 28-34.

31. Sir Arthur Lewis Institute of Social and Economic Studies (2012) Human Development Challenges in a Global Crisis: Addressing Growth and Social Inclusion. Barbados Country Assessment of Living Conditions 2010. Barbados: SALISES, University of the West Indies.

32. Bronte-Tinkew J \& DeJong G (2004) Children's nutrition in Jamaica: do household structure and household economic resources matter? Soc Sci Med 58, 499-514.

33. Choi H \& Marks NF (2011) Socioeconomic status, marital status continuity and change, marital conflict, and mortality. $J$ Aging Health 23, 714-742.

34. Tull ES \& Taylor J (2014) Assessing the association of nativity and acculturation to fast food restaurant use and its relationship to metabolic risk factors among US black with Afro-Caribbean ethnicity. Ethn Dis 24, 438-433.

35. Johnson RK, Driscoll P \& Goran MI (1996) Comparison of multiple-pass 24-hour recall estimates of energy intake with total energy expenditure determined by the doubly labeled water method in young children. J Am Diet Assoc 96, 1140-1144. 
36. Ma Y, Olendzki BC, Pagoto SL et al. (2009) Number of 24-hour diet recalls needed to estimate energy intake. Ann Epidemiol 19, 553-559.

37. Livingstone M \& Robson P (2000) Measurement of dietary intake in children. Proc Nutr Soc 59, 279-293.

38. Räsänen L (1979) Nutrition survey of Finnish rural children. VI. Methodological study comparing the 24-hour recall and the dietary history interview. Am J Clin Nutr 32, 2560-2567.

39. Salehi-Abargouei A, Akbari F, Bellissimo N et al. (2016) Dietary diversity score and obesity: a systematic review and metaanalysis of observational studies. Eur J Clin Nutr 70, 1-9.
40. Setayeshgar S, Maximova K, Ekwaru JP et al. (2017) Diet quality as measured by the Diet Quality Index-International is associated with prospective changes in body fat among Canadian children. Public Health Nutr 20, 456-463.

41. Zhao W, Yu K, Tan S et al. (2017) Dietary diversity scores: an indicator of micronutrient inadequacy instead of obesity for Chinese children. BMC Public Health 17, 440.

42. Sharma S, Cao X, Harris R et al. (2008) Assessing dietary patterns in Barbados highlights the need for nutritional intervention to reduce risk of chronic disease. J Hum Nutr Diet 21, 150-158. 